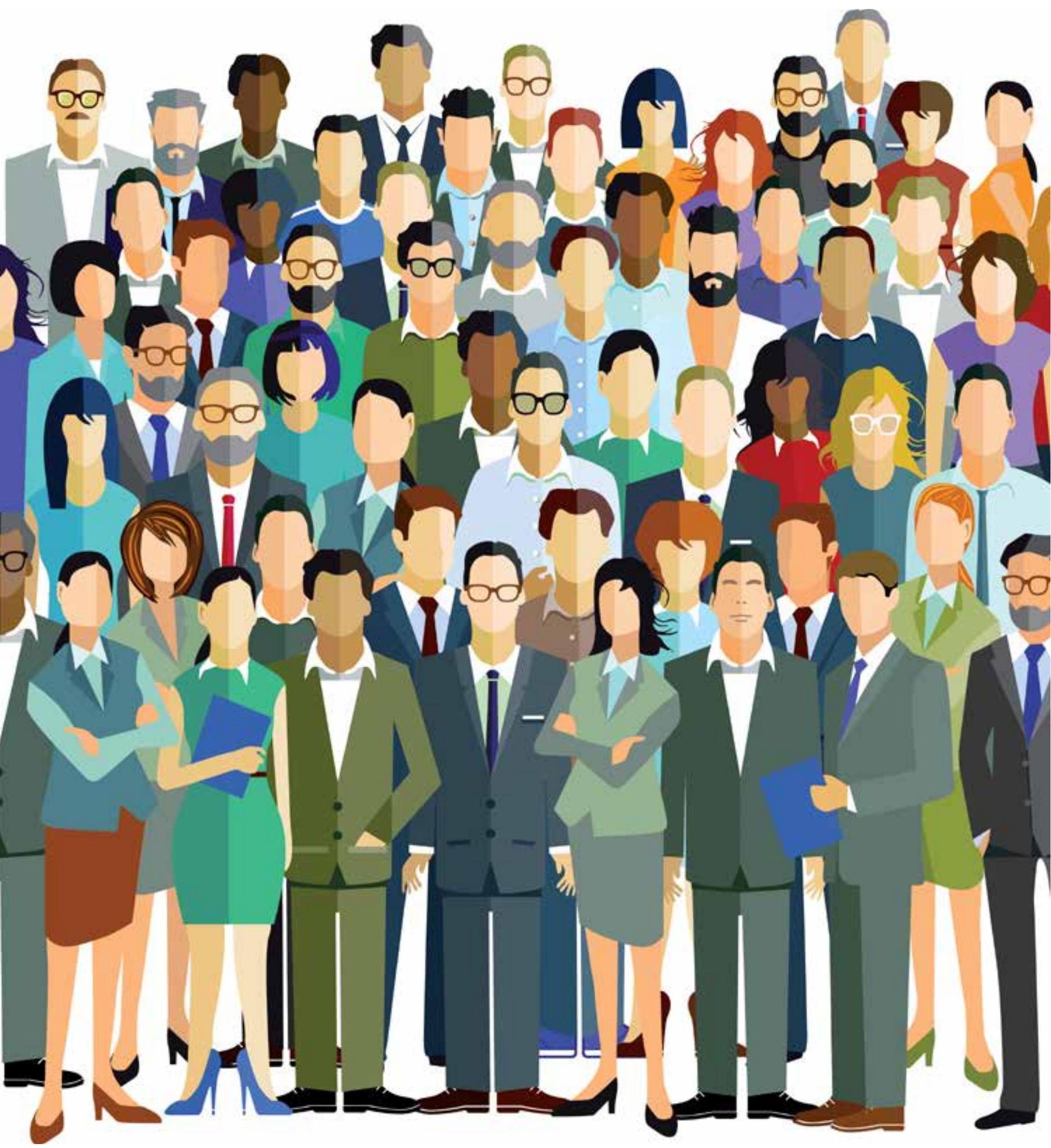


*Doutora em Educação. Professora do Programa de Pós-graduação em Educação da Faculdade de Educação e Diretora de Ensino da Pró-reitoria de Graduação da Universidade Federal de Uberlândia (UFU).

E-mail:

geovana.melo@gmail.com

**Mestre em Educação (UFU). E-mail:

mmkato@umuarama.ufu.br

Recebido para publicação em: 2.7.2015

Aprovado em: 15.2.2016

\section{DOCÊNCIA NA EDUCACC̃̃O SUPERIOR: EM FOCO AS CIÊNCIAS AGRÁRIAS}

\section{TEACHING IN HIGHER EDUCATION: FOCUS ON AGRICULTURAL SCIENCES}

Geovana Ferreira Melo* Marly Nunes de Castro Kato**

\section{Resumo}

O foco do estudo é o desenvolvimento profissional de professores universitários que atuam nas Ciências Agrárias. O objetivo é analisar as inter-relações entre a formação, os saberes e a identidade profissional dos docentes. As análises indicam que o aprendizado da docência ocorre desde o início de sua vida acadêmica. E apontam para a necessidade de promover a articulação entre os professores, para que no trabalho coletivo e integrado em espaços formativos tenham a oportunidade de desenvolver os saberes que certamente se refletirão no aprimoramento constante da formação desenvolvida na educação superior.

Palavras-chave: Docência na Educação Superior. Ciências Agrárias. Desenvolvimento profissional docente. Saberes.

\section{Abstract}

The study focus is the professional development of university teachers who work in the Agricultural Sciences. The purpose is to analyze the interrelationships between education, knowledge and professional identity of teachers. Analyses indicate that the teaching learning occurs from the beginning of their academic life. And it points to the need for promoting the articulation among teachers, so that in the collective and integrated work in formative spaces they have the opportunity of developing the knowledges that will certainly reflect in the constant improvement of the education developed in higher education. 
formar estudantes para enfrentar esse mundo profissional permeado de mudanças e incertezas, conforme Imbernón (2002) alerta, requer do professor universitário densa formação no campo científico de sua área, mas, também, sólida e permanente formação didático-pedagógica.

No sentido de compreender os aspectos referentes ao aprendizado da docência universitária, torna-se fundamental reconsiderar as concepções que sustentam as práticas docentes, uma vez que estão diretamente vinculadas às crenças e aos valores construídos no decorrer da trajetória formativa dos professores. Sendo assim, esta pesquisa visa atribuir maior atenção aos saberes pedagógicos e aos aspectos relacionados à organização da sala de aula como espaço privilegiado de construção do conhecimento e de exercício do pensamento crítico e criativo. E se constitui fonte para a elaboração e implementação de políticas institucionais de desenvolvimento profissional dos docentes universitários.

\section{Docência na Educação Superior: em foco as Ciências Agrárias}

Os professores universitários enfrentam, cada vez mais, as exigências postas pelo cenário de produção acadêmica acelerada, uma vez que o seu sucesso está pautado na quantidade de produções, e não na qualidade do ensino que se desenvolve na graduação. Segundo Pádua:

Há necessidade de compreendermos que a produção do conhecimento é processual, que este processo é histórico, individual e coletivo ao mesmo tempo, derivado da práxis humana e, por isso mesmo, não linear nem neutro, como queria a ciência positivista (PÁDUA, 2012, p. 28).

Esse cenário requer do professor a capacidade de articular, ao mesmo tempo, uma diversidade de tarefas que, muitas vezes, ultrapassam suas possibilidades. O cotidiano universitário requer que o docente assuma diferentes atribuições, como: aulas para planejar, desenvolver e avaliar; pesquisas; extensão; orientações de monografias, teses e dissertações, além de atividades administrativas, como reuniões, comissões, entre outras atividades. Diante desse acúmulo de funções, o professor muitas vezes tem privilegiado a produção do conhecimento científico, em detrimento da qualidade pedagógica da aula universitária.

A formação para a docência vem sendo analisada como característica necessária ao exercício profissional do professor. Essas análises têm ocupado um espaço significativo, pelo menos nos últimos dez anos, nas pesquisas de vários autores, entre os quais Cunha e Broilo (2008), Pimenta (2005), 
Magalhães e Souza (2012), Malusá e Feltran (2005), Melo e Naves (2012), Pachane (2009) e Tardif (2002). O interesse por identificar quem é o docente do ensino superior, seus saberes, como ele desenvolve sua atividade profissional, como aprende a ser professor e como mantém esse aprendizado tem sido preocupação de pesquisadores em âmbito nacional e internacional.

Para Zabalza (2004), o papel do professor restrito a mero transmissor de informação tem sido paulatinamente superado. A docência refere-se à mediação entre os objetos de conhecimento e os estudantes como sujeitos da aprendizagem. Para o autor, "o principal objetivo da formação é equipar os alunos com estratégias de integração das informações" (ZABALZA, 2004, p. 63).

Do ponto de vista didático-pedagógico, até a década de 1990, o ensino agrícola, assim como outros cursos superiores, foi, notadamente, desenvolvido a partir de práticas pautadas em abordagens experimentalistas e comportamentalistas. Porém, com inovações e organização do desenvolvimento agrícola nas questões de sustentabilidade e produtividade, foram surgindo mudanças significativas no sentido de responder a algumas exigências no que é economicamente produtivo e socialmente equitativo.

Essas exigências se refletem diretamente no contexto da aula universitária, ou seja, nas práticas pedagógicas dos professores. No entanto, novas perspectivas para a docência no ensino superior têm sido experimentadas, conforme mostram Pimenta e Anastasiou mencionando a Universidade Federal do Paraná (UFPR):

No Curso de Agronomia da UFPR, pioneiro na implementação do Programa de Avaliação do Docente pelo Discente, a preocupação com a formação dos professores passou a ser constante. As atividades implementadas para a docência, nesse programa, visam principalmente propiciar um espaço de reflexão articulada que contribua com a formação inicial e continuada de educadores para o ensino superior (PIMENTA; ANASTASIOU, 2010, p. 256).

A docência, como campo de atuação profissional, compreende uma complexidade de saberes teórico-práticos que, por sua vez, serão legitimados pela opção individual e pela apropriação de condutas e modelos que marcam a vida acadêmica. Entretanto, como profissão, há desdobramentos a serem considerados, conforme apresenta Dubar (2005, p. 195):

Esse mecanismo básico, centrado na formação e na carreira, é complementado por outro, que conduz "de forma natural" o grupo profissional a multiplicar as regulamentações, as normas estatutárias e os privilégios diferenciados para seus próprios membros. 


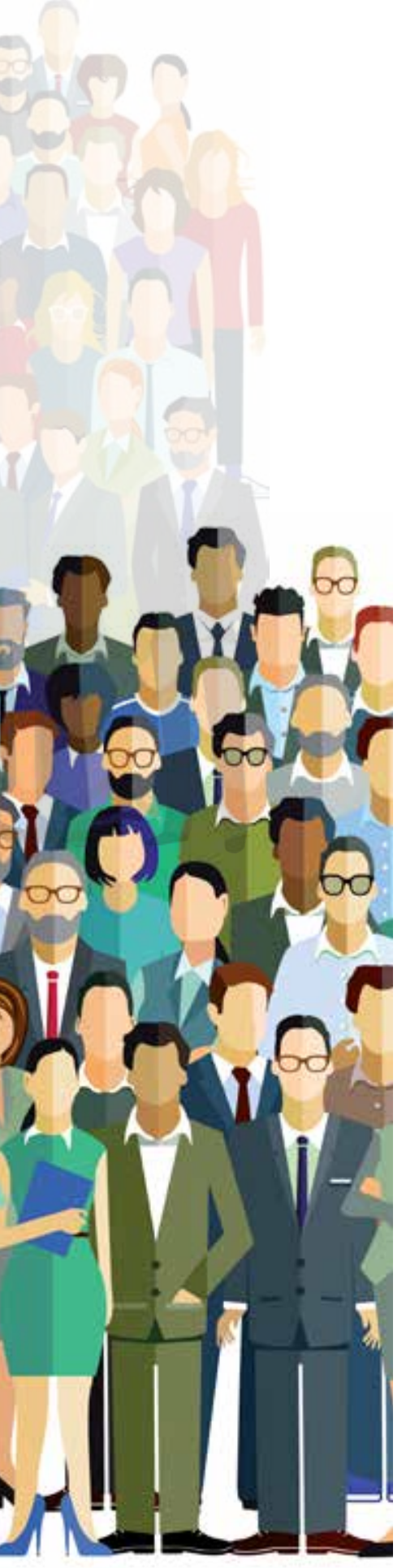

Ao se referir à docência como profissão, é preciso considerar a multiplicidade de tarefas e situações do cotidiano universitário que exigem do professor um denso processo formativo, para além do domínio do campo científico dos conhecimentos que irá desenvolver.

Nessa busca de conceituar a formação do docente universitário, depara-se com os princípios orientadores estabelecidos por Almeida (2012, p. 85), que seriam, inicialmente, superar a tradicional justaposição entre a teoria e a prática, e promover a articulação entre elas. Em síntese, a formação pode ser compreendida a partir da integração entre a dimensão disciplinar e pedagógica dos conteúdos que serão ensinados, além das dimensões éticas e estéticas, igualmente importantes no processo formativo do professor. Desse modo, a formação inicial será considerada o primeiro passo da carreira e deve ser articulada com todas as etapas do desenvolvimento profissional docente.

A docência deve ser entendida como profissão que exige a elaboração de saberes bastante específicos e requer a sistematização de processos formativos que convirjam para o fortalecimento da profissionalização docente. Veiga (2008, p. 15) destaca que "o processo de formação é multifacetado, plural, tem início e nunca tem fim. É inconcluso e autoformativo". Constitui-se, dessa forma, o entretecimento da autoformação com processos de inter-formação, em uma dinâmica que possibilite a constante elaboração e reelaboração das identidades profissionais.

\section{Os sujeitos da pesquisa: professores- agrônomos}

As reflexões aqui apresentadas referem-se a uma pesquisa maior, desenvolvida no Programa de Pós-graduação em Educação da UFU, no curso de Mestrado em Educação. Trata-se de uma pesquisa de abordagem qualitativa, em que grande parte dos dados foi obtida junto aos docentes por meio de questionários, além da análise documental em fontes que abordam aspectos da história do curso e da Universidade.

Os sujeitos da pesquisa são todos docentes do curso de Agronomia de uma universidade federal do Triângulo Mineiro. Essa opção decorreu de estarem ligados diretamente ao processo do ensino aos futuros profissionais engenheiros agrônomos ou profissionais ligados à docência. Por eles, é possível analisar o processo que perpassa a prática pedagógica e construção do docente nas dimensões pessoal e profissional. 
Participaram do estudo 29 docentes do Instituto de Ciências Agrárias, dos quais 26 responderam o questionário de identificação, sendo 20 do gênero masculino e seis do feminino. Essa diferença quanto ao número de professores se justifica também por ser um curso relacionado ao cultivo da terra, cuja atividade, conforme dados do Ministério da Educação/Instituto Nacional de Estudos e Pesquisas Educacionais Anísio Teixeira/ Diretoria de Estatísticas Educacionais (MEC/Inep/Deed), é historicamente masculina. Nesse levantamento sobre funções docentes em exercício, do ano de 2011, nos cursos de graduação e sequenciais, tanto presencial quanto a distância, oferecidos pelas instituições brasileiras de educação superior, nos cursos da área de Ciências Exatas e da Terra, a presença feminina é inferior a 50\% em todos os cursos. Campos (2010, p. 98), ao considerar em sua pesquisa a distribuição por sexo nas diversas áreas do conhecimento, verificou "o maior número de docentes do sexo masculino na área das Ciências Exatas e da Terra: 154,16\% e 92,9\% nas áreas de Ciências Biológicas. Enquanto que nas Ciências Agrárias $89,9 \%$ são do sexo masculino e $64 \%$ do sexo feminino".

\section{Gráfico 1 - Distribuição dos professores por gênero}

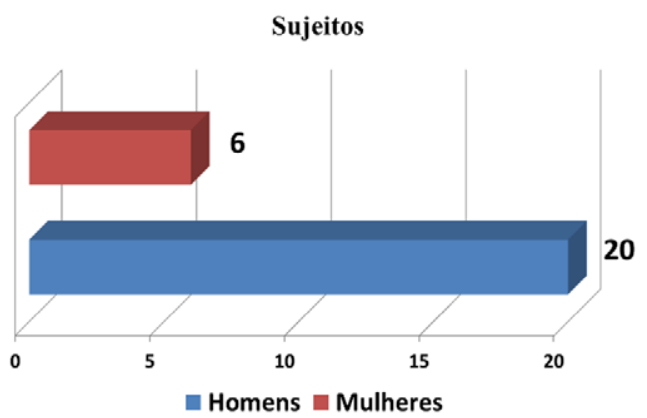

Fonte: Questionário de Identificação obtido pelas pesquisadoras junto aos docentes do Curso de Agronomia, 2013.

Esse fato remete a questões históricas. O lugar de destaque da docência do ensino superior nas áreas de Ciências Agrárias ainda é ocupado por profissionais do sexo masculino, porém, gradativamente, a mulher tem se apresentado nesse cenário.

\section{Gráfico 2 - Formação Acadêmica na Pós-graduação}

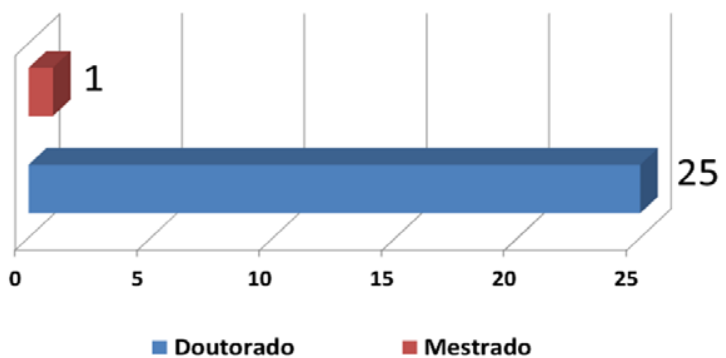

Fonte: Questionário de Identificação obtido pelas pesquisadoras junto aos docentes do Curso de Agronomia, 2013. 
No conjunto de docentes, 25 possuem doutorado. Obtiveram, assim, uma formação desenvolvida na pós-graduação, em que o foco está na competência científica. A Lei n. 9.394/96 (Lei de Diretrizes e Bases da Educação Nacional), em seu artigo 66, determina apenas que "a preparação para o exercício do magistério superior far-se-á em nível de pós-graduação, prioritariamente em programas de mestrado e doutorado". Nesse sentido, essa preparação se efetiva pelo cumprimento da disciplina "Metodologia do Ensino Superior", ministrada nos cursos de pós-graduação. No entanto, para Ferenc e Mizucami (2005, p. 5): “O saber para ensinar - saber das ciências da educação, saberes metodológicos - por muito tempo foi visto como um simples adereço aos saberes diciplinares". Todo o processo de preparo para a docência envolve a oportunidade de experimentar "mudar de lado" - ou seja, de aluno, para bacharel e professor. Essa condição é oferecida de forma elementar na pós-graduação, conforme atividades descritas no Gráfico 3.

\section{Gráfico 3 - Atividades que contribuíram com a formação para professor}

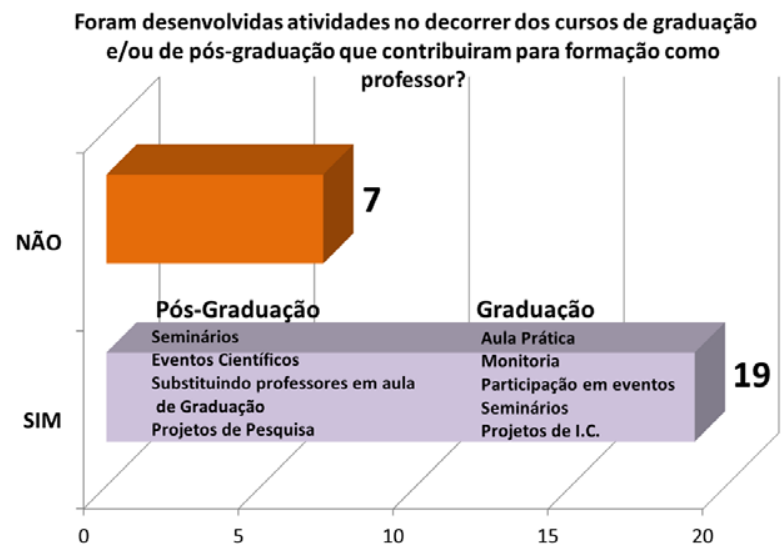

Fonte: Questionário Ampliado obtido pelas pesquisadoras junto aos docentes do Curso de Agronomia, 2013.

Para este estudo, foi identificado que $27 \%$ dos docentes consideram que não houve atividades no decorrer de sua formação na graduação e pós-graduação que contribuíssem para sua formação como professor. Para Cunha (2007, p.21), “o mundo acadêmico revela o valor que dá à pesquisa em detrimento do ensino [...] mas os saberes da docência são distintos daqueles requeridos para a pesquisa". Essa constatação, associada à representatividade identificada na pesquisa, remete também a questões ligadas à pouca preocupação das legislações na área da Educação quanto à formação do docente para o exercício profissional. Diante disso, o professor terá que buscar alternativas individuais ou institucionais para desenvolver conhecimentos específicos para sua atuação docente. 
Os demais docentes - ou seja, 73\% - consideram que houve atividades no decorrer do seu curso de graduação e pós-graduação que contribuíram para sua formação como professor. As atividades descritas cumprem sua importância por ordem de apresentação. Em outros termos, na graduação, a maioria desses docentes elegeram as aulas práticas como a principal atividade para o preparo da docência. Isso se justifica na visão de Darido (1995, p. 3), de que a "articulação entre teoria e prática exige uma organização que possibilite a abordagem de todos os princípios teóricos junto à prática, inclusive, em vários momentos, simultaneamente à prática".

Outra atividade destacada foi a monitoria, conforme define Portela et al. (2013, p. 39): "As atividades realizadas pelo monitor são permeadas pela reflexão sobre questões referentes ao ensino, à pesquisa e à extensão".

Quanto à participação em eventos, é uma das oportunidades de ampliar os horizontes em relação ao curso escolhido e, inclusive, favorecer uma aproximação com a formação continuada do docente em atividade. Na sequência, estão os projetos de iniciação científica que, certamente, são considerados como incentivos para o posterior envolvimento no âmbito da pós-graduação, tendo sido os seminários considerados mais relevantes para a formação do professor.

Os seminários atendem à LDB, que evidencia o exercício da docência nos programas de pós-graduação. Na ementa da disciplina do Programa de Pós-graduação em Agronomia da UFU, com carga horária de 30 horas semestrais, consta o seguinte objetivo: "Proporcionar ao aluno o treinamento para preparação e apresentação de assuntos didáticos e de trabalhos técnicos científicos em público". Embora o termo "treinamento" remeta ao paradigma conservador de educação, na ementa, de forma geral, subjaz à ideia do processo formativo voltado para a dimensão didático-pedagógica. Com isso, o aluno tem a oportunidade de vivenciar desde o estudo do tema até sua apresentação.

Essa disciplina compõe a estrutura curricular do Programa de Pós-graduação em Agronomia da universidade pesquisada. O aluno, ao cursar essa disciplina, tem a oportunidade de apresentar um tema e ser avaliado a partir de sua exposição. Nesse sentido, além de o aluno ter contato com novas abordagens teóricas e didáticas, é possibilitado o despertar do senso crítico em relação à sua atuação e à dos colegas. Em destaque também estiveram os eventos científicos, substituição de professores e, por último, os projetos de pesquisa.

Ainda dentro da categoria da formação, foi oportuno realizar uma revisão teórica quanto às tendências pedagógicas tradicionais e progressistas que, certamente, respaldam as concepções de docência e aprendizagem expressadas pelos sujeitos da pesquisa. Essa relação possibilita compreender sob

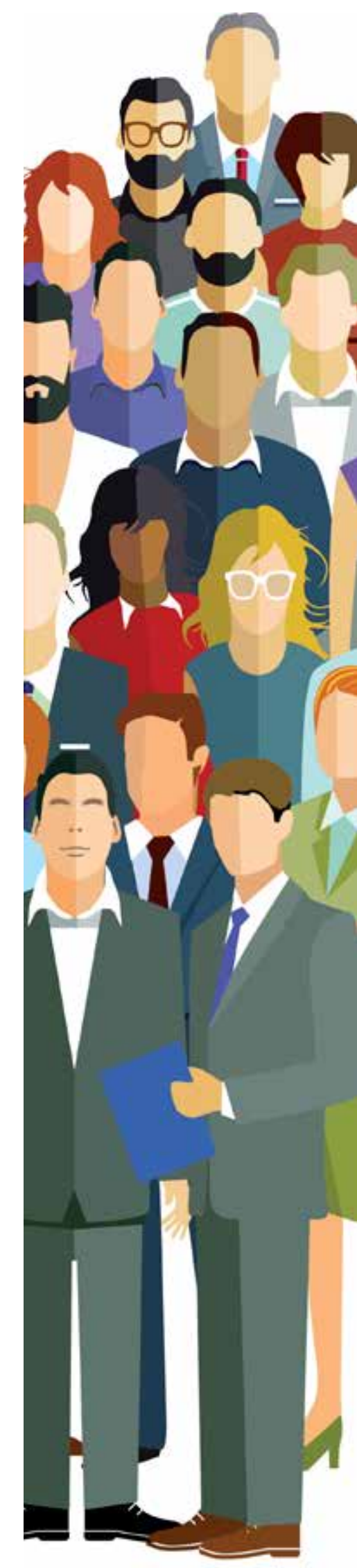


quais pressupostos teóricos estão emergindo as práticas dos docentes, possibilitando, assim, compreender um pouco mais do processo de construção da profissão do docente agrônomo.

Em questões abertas do questionário ampliado, as respostas dos docentes, quando perguntados sobre "O que é ser professor" e "O aluno aprendeu bem quando...", possibilitaram encontrar explicações de temas que esclarecem concepções importantes a respeito de educação, processo ensino-aprendizagem e formação. A análise de grande parte das respostas evidenciou determinadas características que emergem da pedagogia tradicional e da pedagogia progressista. Ao refletir sobre o conceito de pedagogia, identifica-se como sendo a habilidade do docente para compartilhar com o discente o conhecimento.

Na retrospectiva histórica, a Pedagogia Tradicional tem sua origem no século 18 e até os dias atuais ainda é aplicada. Seu foco principal é o conteúdo e o professor. Seu método de ensino está centrado na atividade do docente por meio da aula expositiva, em que os modelos podem ser apresentados aos alunos. Nessa vertente pedagógica, as atividades escolares constituem meramente a exploração dos conteúdos de ensino já sistematizados nos livros didáticos ou previstos pelos programas oficiais, cabendo ao professor a centralidade do ensino, como na visão de Libâneo (1994), - - - $\quad$ fazendo os exercícios repetitivos, os alunos estariam graA atividade vando o assunto para depois reproduzi-lo. Ao aluno reda educação quer o uso da memória, cuja função específica é reter o implica

superar

o fazer tradicional que lhe é transmitido pelo professor.

Essas questões trazem reflexões relacionadas à concepção de docência e de aprendizagem. A primeira não pode se reduzir ao espaço escolar. Pois a atividade da educação implica superar o fazer tradicional e se dispor a constantemente preparar para aquisição de habilidades, para enfrentar os desafios de uma profissão cujo princípio formativo está nas inúmeras experiências como aluno em diferentes idades e convivendo com diferentes professores. Elaborar e mobilizar saberes complementares à formação profissional (experiência, campo específico e pedagógico) favorece ao docente sua constante adaptação a uma profissão que tem como meta proporcionar momentos significativos aos discentes, criando oportunidades de monitorias, trabalhos e seminários, legitimando o ato de ensinar e aprender. Essa relação Pimenta e Anastasiou (2010, p. 205) destacam a seguir: 
A ação de ensinar, se conduzida de acordo com os fins educacionais, decorreria à ação de aprender [...] a ação de ensinar é definida na relação com a ação de aprender, pois, para além da meta que revela a intencionalidade, o ensino desencadeia necessariamente a ação de aprender (PIMENTA; ANASTASIOU, 2010, p. 205).

Quanto à concepção de aprendizagem, envolve um processo de apreensão do conhecimento de forma crítica, transformadora e apto a superar os desafios impostos pela sociedade para o exercício da profissão escolhida. Nessa concepção, a compreensão tem um papel relevante, pois representa para Pimenta e Anastasiou (2010, p. 50) "um dos elementos constitutivos do processo de construir o conhecimento". Além desse elemento, destaca-se também o valor do uso da atenção, da disciplina e dos registros, abstendo-se o uso exclusivo da memória e da aceitação passiva do que é proposto pelo professor. Um aprendizado que promove a interdisciplinaridade entre as várias áreas do saber proporciona aos discentes a autonomia para resolverem os problemas humanos e sociais.

\section{A identidade docente}

O processo de identidade profissional docente é algo que remete a análises profundas e complexas, pois ser docente perpassa por uma história individual e coletiva. Afinal, é a construção do trabalho do professor.

Ao analisar a identidade profissional, é nítido ver refletidas nela as questões pessoais e culturais às quais o docente está submetido. Por isso, é fundamental nessa relação dele com o mundo, com tantos conhecimentos técnico-científicos e metodológicos, desenvolver a capacidade de refletir sobre a própria prática com o objetivo de construí-la mais coerente e comprometida. Para Pimenta e Anastasiou (2010,

p. 189), “a identidade não é um dado imutável nem externo, mas se dá em processo, na construção do sujeito historicamente contextualizado".

As identidades vão se construindo e tecendo uma teia de interferências de valores individuais e coletivos, contribuindo para construção da professoralidade. Os professores, ao serem questionados a respeito de quais são seus "pontos fortes", ou seja, o que consideram que fazem bem, destacaram principalmente a




formação intelectual e capacidade de expor claramente o conteúdo, conforme o gráfico a seguir.

\section{Gráfico 4 - Pontos fortes como professor}

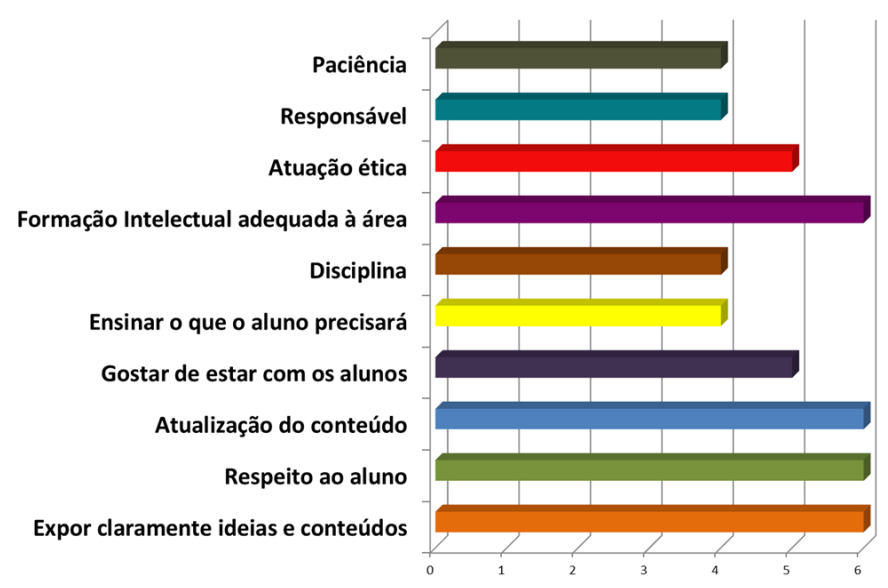

Fonte: Questionário Ampliado obtido pelas pesquisadoras junto aos docentes do Curso de Agronomia, 2013.

Na visão dos sujeitos da pesquisa, a questão da formação intelectual, atualização do conteúdo e a exposição clara das ideias foram os aspectos ressaltados, que coadunam com as exigências da sociedade contemporânea, cuja valorização está centrada na formação para a profissão e na especialização de áreas.

Quando o docente define sua função, certamente, isso foi fruto de reflexões embasadas em experiências contruídas ao longo de sua atuação. Os dados também revelam que o foco principal está relacionado ao conhecimento científico, mesmo porque eles não tiveram em sua formação inicial disciplinas que os ajudassem a ter uma identidade forte como docente do ensino superior. Porém, ao se autoavaliar, ficou eminente a parte melhor que ele foi capaz de conquistar. A condição de expressar com clareza remete a questões ligadas à capacidade de fazer uso eloquente de elementos que foi capaz de apropriar para chegar a uma conclusão.

\section{Os saberes docentes}

O docente do ensino superior, com raras exceções, aprende a ensinar, ensinando, em um movimento constante de "ensaio e erro". No cotidiano, sua prática vai sendo construída e consolidada a partir de crenças pautadas em saberes da experiência. Nesse sentido, Tardif (2000, p. 11) argumenta que: "os saberes profissionais são saberes trabalhados, saberes laborados, incorporados no processo de trabalho docente, que só tem sentido em relação às situações de trabalho". 
Assim, o docente do ensino superior está diante de um paradoxo. De um lado está a universidade, sujeita a um projeto social para o ensino superior voltado à formação de profissionais para atender às exigências do capital. Por outro lado, a atividade docente requer do profissional que desenvolva o conhecimento científico objetivando a formação ética e cidadã dos estudantes, o que exige a aquisição de um conjunto de saberes e habilidades que vão além do domínio de um conhecimento historicamente acumulado.

Não se trata de relacionar a docência com saberes vinculados somente à transmissão de conhecimentos, mas, sim, conforme afirma Melo e Santos (2010, p. 361):

O exercício da docência não é algo simples. Trata-se de um fazer complexo que exige do docente uma formação para além do domínio científico de sua área de formação e atuação - imprescindível - mas não o bastante para o desenvolvimento do processo de ensino-aprendizagem. Nesse sentido, torna-se imperiosa a elaboração de conhecimentos teóricos e práticos relacionados à docência, compreendida com um ofício que exige o domínio de vários saberes.

No cotidiano, a autonomia da profissão docente vai se consolidando e as reflexões sobre os saberes necessários vão se desvelando como um desafio a ser apropriado para o exercício dessa profissão. $\mathrm{Na}$ teia de relações que envolve o espaço escolar do ensino superior, o docente requer, além dos saberes científicos e didático-pedagógicos, os saberes da experiência. De acordo com Melo e Santos (2010), o saber experiencial nasce e é validado diretamente pela maneira como o professor age. Enfim, são saberes necessários para responder aos desafios de uma profissão que tem peculiaridades e singularidades, pois lida diretamente com a formação de pessoas em pleno processo de construção de suas profissões.

O planejamento, enquanto parte do processo didático pedagógico, tem sido alvo de diferentes pesquisas de autores, como Anastasiou e Alves (2004), Garcia (2009), Gil (2007), Luckesi (1998) e Vasconcellos (2009). Por ele, o docente universitário se coloca como sujeito do processo educativo, tendo em vista os objetivos do plano de ensino. 


\section{Gráfico 5 - Sobre o planejamento da aula ou conteúdo}

Sobre o planejamento de uma aula você pode afirmar que:

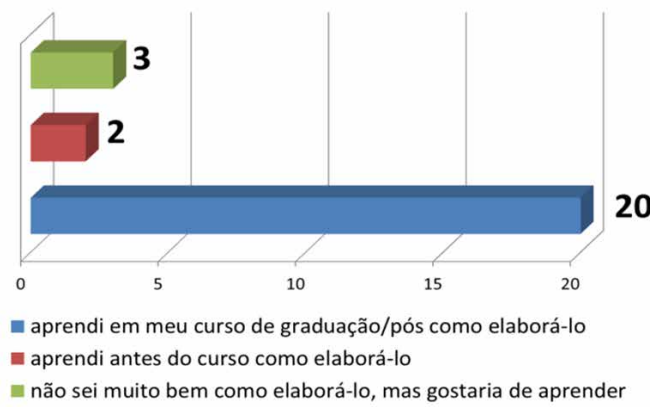

Fonte: Questionário Ampliado obtido pelas pesquisadoras junto aos docentes do Curso de Agronomia, 2013.

Diante desse panorama, entende-se que sem os improvisos a prática docente assume características mais inovadoras e eficazes. Nessa pesquisa, a maioria dos docentes identificou que aprenderam como elaborar o planejamento. Entretanto, pode-se inferir que essa afirmativa está relacionada à flexibilidade, que é uma das características principais do planejamento, pois planejar é uma tarefa complexa, que envolve, além da elaboração, a execução e avaliação da prática pedagógica.

Outra dimensão didático-pedagógica da docência universitária analisada está relacionada com a avaliação da aprendizagem. Perguntados sobre como eles julgam ter aprendido a avaliar, as respostas no Gráfico 6 expressam a concepção de avaliação dos docentes do curso de Agronomia.

\section{Gráfico 6 - Avaliação da aprendizagem}

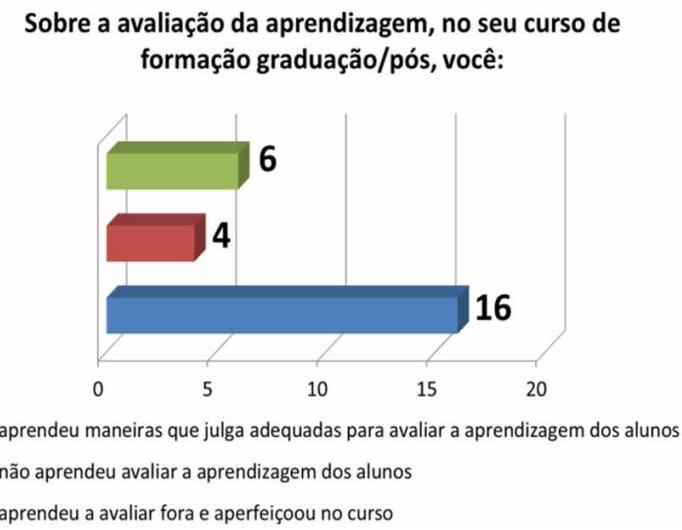

Fonte: Questionário Ampliado obtido pelas pesquisadoras junto aos docentes do Curso de Agronomia, 2013. 
A avaliação da aprendizagem é considerada importante ferramenta para que o professor possa refletir sobre o processo de ensinar e como os estudantes se desenvolvem. A questão da avaliação tem uma relação direta com o processo ensino-aprendizagem, pois será a oportunidade para conhecer a situação em que se encontram os estudantes e, se necessário, promover modificações no processo. Nessa pesquisa, $17 \%$ dos docentes do curso de Agronomia julgam compreender sua complexidade, sendo que, desses docentes, somente $4 \%$ não se dispõem a mudar a forma de avaliar. Entretanto, $83 \%$, mesmo expressando que aprenderam maneiras que julgam adequadas para avaliar a aprendizagem dos alunos, estão abertos a buscar novas alternativas para realizá-la. Essa questão está intrinseca mais à ação docente do que à condição de discente, porque a avaliação não é um ato simples, significa, na ótica de Luckesi (2014, p. 120):

[...] o ato de avaliar a aprendizagem dos nossos educandos implica que, nós educadores, estamos atentos aos nossos educandos e desejosos de que eles aprendam, diagnosticando o que ocorre com eles e as razões pelas quais isso ocorre e tomando decisões para intervenções adequadas, tendo em vista sua melhoria em termos de aprendizagem e de seu consequente crescimento.

Compreende-se que a avaliação é parte integrante do processo de ensinoaprendizagem e, por ela, o docente pode identificar os avanços e as fragilidades que envolvem o aprendizado.

\section{O desenvolvimento profissional}

O docente universitário constrói seu desenvolvimento profissional, lidando com a subjetiva dinâmica de construir civilizações com seres que, na maioria das vezes, são excluídos pela falta da coletividade. Daí a concepção de que para ensinar não basta só o conhecimento científico, requer o desenvolvimento de habilidades humanas para que a prática docente seja efetiva.

Nos estudos de Huberman (2000), nos primeiros anos de exercício profissional do professor, ele organiza sua prática, em geral, por meio de estratégias
Para ensinar não basta só o conhecimento científico, requer o desenvolvimento de habilidades humanas

•........ 
A identidade do agrônomo docente, a formação, os saberes foram diagnosticados como a base de sua formação pautada em conteúdos específicos. Os aspectos pedagógicos e conhecimentos relacionados aos sólidos valores humanos certamente podem contribuir para uma vida verdadeiramente cidadã.

Tal perspectiva apresenta às universidades o desafio de assumirem a responsabilidade pela criação e consolidação de programas institucionais de formação e desenvolvimento profissional de seus professores, o que reverbera na melhoria do ensino.

O aprendizado da docência universitária deverá, portanto, ser fomentado, instigado e instituído nos espaços universitários. O incremento dos processos de formação inicial e continuada, por meio da interlocução direta entre graduação, pós-graduação e programas de formação e desenvolvimento profissional dos docentes, aliado à melhoria das condições de trabalho, sem dúvida terá reflexo no aprimoramento constante da formação desenvolvida no interior das universidades.

\section{Referências}

ALMEIDA, M. I. Formação do professor do ensino superior: desafios e políticas institucionais. São Paulo: Cortez, 2012. (Coleção Docência em formação: ensino superior).

ANASTASIOU, L. G. C.; ALVES, L. P. Processo de ensinagem na universidade: pressupostos para as estratégias de trabalho em aula. Joinville: Universille, 2004.

BEHRENS, Marilda Aparecida. O paradigma da complexidade na formação e no desenvolvimento profissional de professores universitários. Educação, Porto Alegre, n. 3, p. 439-455, 2007.

BRASIL. Lei n. 9.394, de 20 de dezembro de 1006. Estabelece as diretrizes e bases da educação nacional. Diário Oficial da União, Brasília, DF, 23 dez. 1996. Disponível em: <http://www.planalto.gov.br/ccivil_03/leis//9394.htm>. Acesso em: 29 fev. 2016.

CAMPOS, V. T. B. Marcas indeléveis da docência no ensino superior: representações relativas à docência no ensino superior de pós-graduados de Instituições Federais de Ensino Superior. 2010. 399 f. Tese (Doutorado em Educação) - Faculdade de Educação, Universidade de São Paulo, São Paulo, 2010.

CAVALLET, V. J. A formação do engenheiro agrônomo em questão: a expectativa de um profissional que atenda as demandas sociais do século XXI. $133 \mathrm{f}$. (Tese de Doutorado) - Universidade de São Paulo, São Paulo, 1999.

CRUZ, M. F. Desarrollo professional docente. Granada: Grupo Editorial Universitário, 2006. p. 9-189.
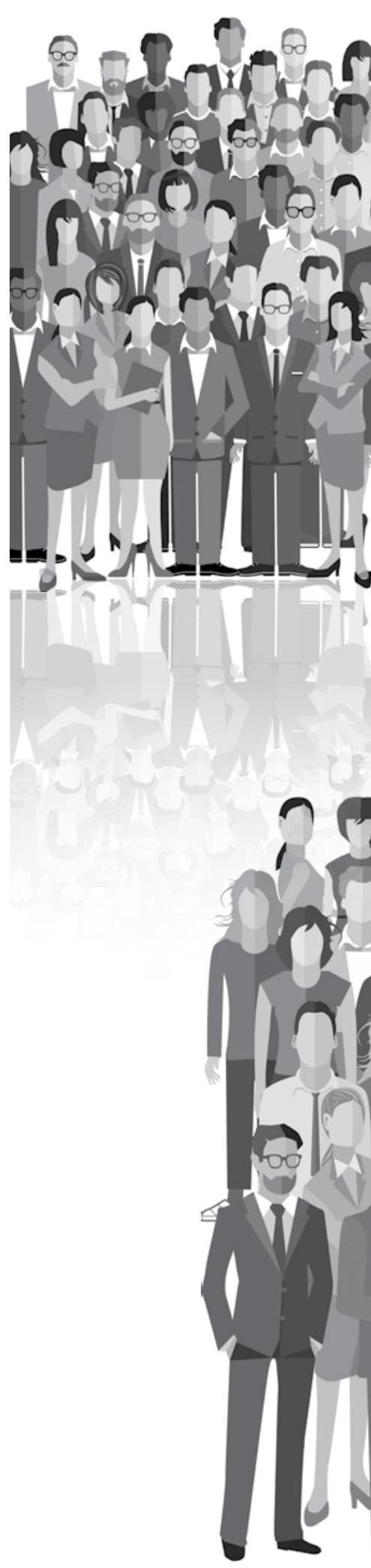


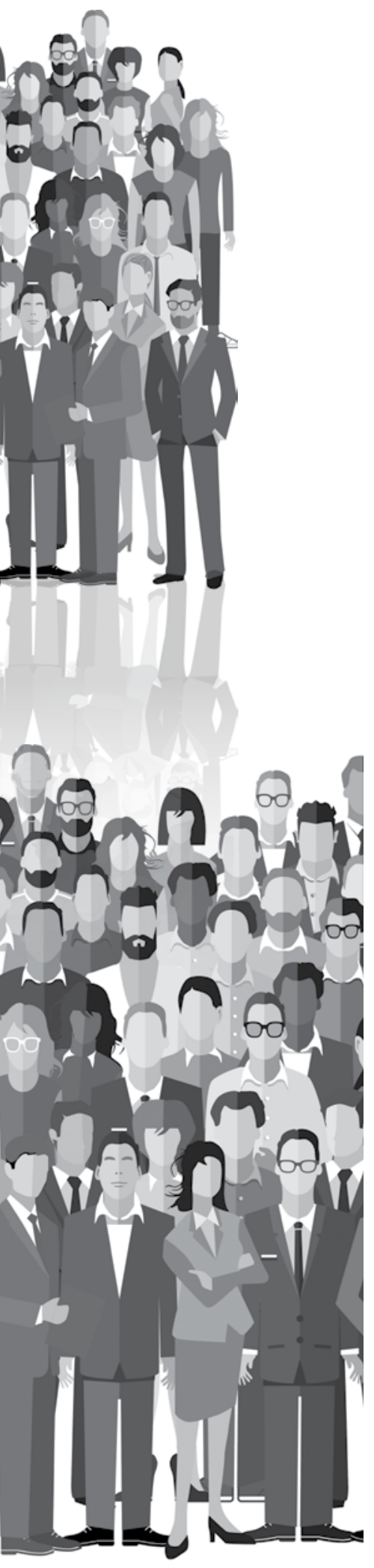

CUNHA, Maria Isabel. Reflexões e práticas em pedagogia universitária. Campinas: Papirus, 2007.

CUNHA, Maria Isabel; BROILO, C. L. Pedagogia universitária e produção do conhecimento. Porto Alegre: Edipucro, 2008.

DARIDO, Suraya Cristina. Teoria, prática e reflexão na formação do profissional em educação física. Revista MOTRIZ, Rio Claro, v. 1, n. 2, p. 124-128, dez. 1995.

DUBAR, C. A socialização: construção das identidades sociais e profissionais. Tradução de Andrea Stahel M. da Silva. São Paulo: M. Fontes, 2005.

FERENC, A. V. F.; MIZUKAMI, M. G. N. Formação de professores, docência universitária e o aprender a ensinar. In: CONGRESSO ESTADUAL PAULISTA SOBRE FORMAÇÃO DE EDUCADORES, 7., 2005, Águas de Lindóia. Anais... Águas de Lindóia: Unesp Pró- Reitoria de Graduação, 2005. V.1.

GARCIA, J. Avaliação e aprendizagem na educação superior. Estudos em Avaliação Educacional, São Paulo, v. 20, n. 43, p. 201-213, maio/ago. 2009. Disponível em: $<$ http://www.fcc.org.br/pesquisa/publicacoes/eae/arquivos/1489/1489.pdf $>$. Acesso em: 18 mar. 2014.

GIL, A. C. Didática no ensino superior. São Paulo: Atlas, 2007.

HUBERMAN, M. O ciclo de vida profissional dos professores. In: NOVOA, A. Vidas de professores. Porto: Porto Ed., 2000. p. 31-62.

IMBERNÓN, F. A educação no século XXI: os desafios do futuro imediato. Porto Alegre: Artmed, 2002.

ISAIA, S. M. A. Desafios à educação superior; pressupostos a considerar. In: RISTOFF, D.; SEVIGNANI, P. (Org.). Docência na educação superior. Brasília, DF: INEP, 2006. p. 63-84. (Coleção Educação superior em debate, v. 5).

LIBÂNEO, J. C. Didática. São Paulo: Cortez, 1994.

LUCKESI, Cipriano Carlos. Avaliação ou verificação?: o que pratica a escola? São Paulo: FDE, 1998. p. 71-80. Disponível em: <http://www.crmariocovas.sp.gov.br/pdf/ ideias_08_p071-080_c.pdf>. Acesso em: 18 mar. 2014.

MAGALHÃES, S. M. O.; SOUZA, R. C. C. R. (Org.). Formação de professores: elos da dimensão complexa e transdisciplinar. Brasília, DF: Liber, 2012.

MALUSÁ, Silvana; FELTRAN, R. C. S. (Org.). A prática da docência universitária. 2. ed. São Paulo: Factash Ed., 2005. v. 2.

MELO, G. F.; NAVES, Marisa Lomônaco de Paula (Org.). Didática e docência universitária. Uberlândia: EDUFU Ed., 2012. v. 1.

MELO, G. F; SANTOS, P. P. Docência universitária: percepções a partir do quadro teórico dos saberes docentes. Ensino Em-Revista, Uberlândia, v. 17, n. 2, p. 355-376, jul./ dez. 2010. 
NOVOA, A. Vidas de professores. Porto: Porto Ed.,1992.

PACHANE, Graziela Giusti. Formação de professores para a docência universitária no Brasil: uma introdução histórica. Cadernos de Filosofia e Psicologia da Educação, Vitória da Conquista, ano 7, n. 12, p. 25-42, 2009.

PÁDUA, E. M. M. Metodologia da pesquisa: abordagem teórico-prática. 17. ed. Campinas: Papirus, 2012.

PIMENTA, S. G. Formação de professores: identidade e saberes da docência. In: PIMENTA, S. G. (Org.). Saberes pedagógicos e atividade docente. 4. ed. São Paulo: Cortez, 2005. p. 15-34.

PIMENTA, S. G.; ANASTASIOU, L. G. C. Docência no ensino superior. São Paulo: Cortez, 2010.

PORTELA, V. O. et al. A monitoria como mediadora do ensino de desenho técnico no Curso de Agronomia da UFFS, Cerro Largo/RS. In: SEMINÁRIO INTERDISCIPLINAR DE ENSINO, PESQUISA E EXTENSÃO, 18, 2013. Anais do... Universidade Federal da Fronteira Sul, 2013. v. 2.

TARDIF, M. Saberes docentes e formação profissional. Petrópolis: Vozes, 2002.

TARDIF, M. Saberes profissionais dos professores e conhecimentos universitários. Revista Brasileira de Educação, São Paulo, n. 13, p. 3-24, jan./ abr. 2000.

VASCONCELLOS, C. Planejamento: projeto de ensino-aprendizagem e projeto político pedagógico: elementos metodológicos para elaboração e realização. 19. ed. São Paulo: Libertad, 2009.

VEIGA, I. P. A. Profissão professor: até quando? Revista Pleiade, Foz do Iguaçu, v. 1, n. 1, p. 29-40, jul./dez. 2008.

ZABALZA, M. A. 0 ensino universitário: seu cenário e seus protagonistas. Porto Alegre: Artmed, 2004. 
